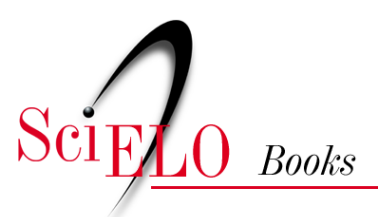

\title{
Conclusões e recomendações
}

\author{
Hellio Campos
}

\section{SciELO Books / SciELO Livros / SciELO Libros}

CAMPOS, H. Conclusões e recomendações: os seguidores da escola de Bimba. In: Capoeira regional: a escola de Mestre Bimba [online]. Salvador: EDUFBA, pp. 288-306. ISBN 978-85-2321727-3. Available from: doi: $10.7476 / 9788523217273.0023$. Also available in ePUB from: http://books.scielo.org/id/p65hq/epub/campos-9788523217273.epub.

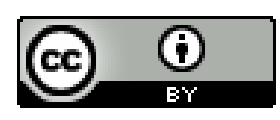

All the contents of this work, except where otherwise noted, is licensed under a Creative Commons Attribution 4.0 International license.

Todo o conteúdo deste trabalho, exceto quando houver ressalva, é publicado sob a licença Creative Commons Atribição 4.0.

Todo el contenido de esta obra, excepto donde se indique lo contrario, está bajo licencia de la licencia Creative Commons Reconocimento 4.0. 


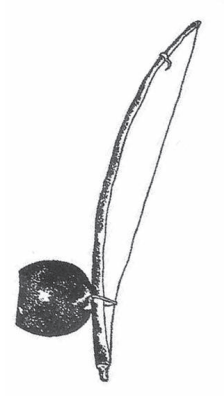

Conclusões e recomendações

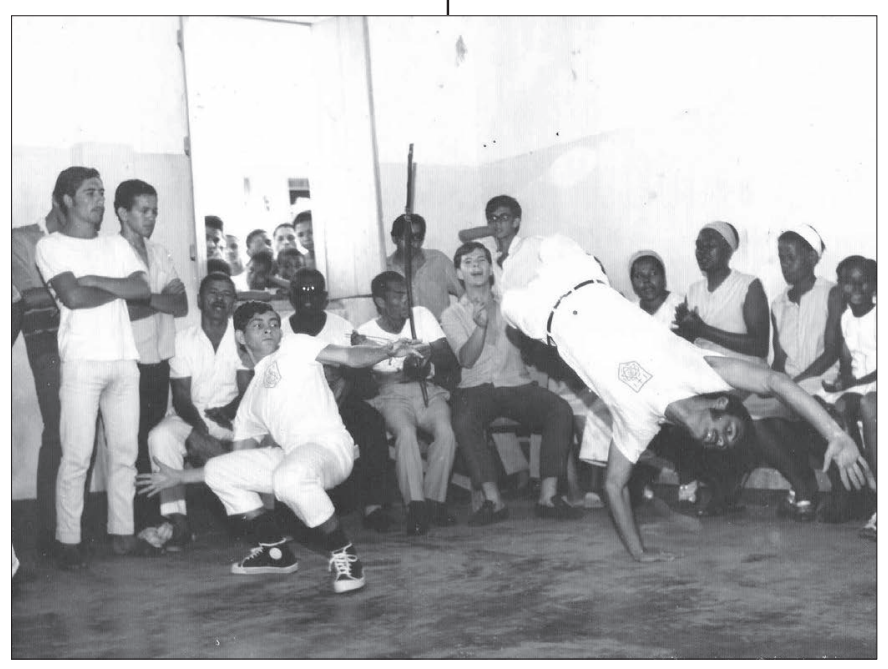


E sta investigação desenvolveu-se a partir de três direções básicas e complementares: na primeira, nos ocupamos exaustivamente da fundamentação teórica, buscando alargar os conhecimentos e facilitar uma análise minuciosa e criteriosa dos dados obtidos em entrevistas. Na segunda, nos debruçamos sobre a biografia de Mestre Bimba, objetivando aprofundar o conhecimento de sua vida pública, da vida privada, de sua liderança na capoeira, da criação da Capoeira Regional e principalmente do mito Mestre Bimba, o rei da capoeira. Na terceira direção, nos inclinamos atentamente para a pesquisa empírica, objetivando a análise dos conteúdos obtidos nas entrevistas com os alunos de Mestre Bimba, na sua maioria em vídeo, e por meio de questionário previamente respondido pelos mestres, contramestres e professores de capoeira da atualidade. Vale registrar que nesta fase também foi contemplada a observação direta obtida nos eventos de capoeira, dos quais este pesquisador participou intensamente.

De posse da análise dos resultados e das evidências encontradas neste estudo, podemos finalmente responder à questão principal: Qual era a metodologia de ensino e a ação pedagógica que usava Mestre Bimba para ensinar a Capoeira Regional e quais seus desdobramentos na formação educacional, cultural e de filosofia de vida dos seus alunos?

Nesta exposição, partimos de nosso objetivo geral: analisar a metodologia utilizada por Mestre Bimba para o ensino da Capoeira Regional, bem como os desdobramentos decorrentes desta ação pedagógica na formação educacional e cultural e na filosofia de vida de seus alunos. Em seguida, tratamos dos objetivos específicos listados na primeira parte deste estudo.

Em nossa investigação, encontramos informações desencontradas sobre o perfil de Mestre Bimba, relativas ao seu relacionamento com pessoas, especialmente com seus alunos: alguns afirmaram ser Mestre Bimba um homem fechado, introvertido e que somente aparentava ser alegre e extrovertido nos dias de festas, durante os eventos, batizados, formaturas e apresentações folclóricas do seu grupo. Alguns informantes disseram ser ele um sujeito alto, forte, disciplinador embrutecido, chegando mesmo a ser grosseiro, o que coadunava com a sua reduzida escolaridade formal.

Por outro lado, nos deparamos com informes controversos, que asseveraram ser Bimba um homem simples, semi-analfabeto, com uma conduta que se utilizava da autoridade sem ser autoritária, mas disciplinador, educador, amigo dos seus alunos, preocupado com 
os seus, a exemplo das viagens que empreendia juntamente com suas baianas, tocadores e alunos, quando assumia toda a responsabilidade, procurando o bem-estar dos seus "comandados", como se reportou Nalvinha: "meu pai se preocupava para que tivéssemos boa alimentação, ficássemos em bons hotéis e o conforto dos seus alunos". Cafuné, Escurinho, Sariguê e Angoleiro distinguiram, sobretudo, o lado afetivo de Bimba contando detalhes em que Bimba demonstrava ser carinhoso.

Outros entrevistados disseram considerar Mestre Bimba um pai, um orientador, um exemplo de vida; um homem dotado de sabedoria, um gênio, um conselheiro preocupado, que ensinava muito mais que simplesmente capoeira, ensinava a viver. Ensinava a arte de gingar na vida.

Para os capoeiristas da nova geração, os mestres, contramestres e professores de capoeira, Mestre Bimba representa um mito, um símbolo de resistência, um revolucionário; o criador de algo novo, o descobridor de uma capoeira diferente, contundente, eficiente; um homem que mudou o rumo da história, um líder, uma pessoa dotada de inteligência emocional; um guerreiro, um sujeito forte, lutador e que acreditava no seu ideal; uma pessoa perseverante, de forte personalidade, um grande estrategista, uma pessoa que deve ter sofrido muitos preconceitos, mas soube trilhar seu caminho, sem olhar para trás.

Pela análise dos depoimentos, encontramos evidências do reconhecimento, do apreço, da admiração, do respeito e da reverência, que revelam ser Mestre Bimba um mito, concebido na imagem de um sujeito iluminado, criador e que enxergava à frente do seu tempo; um exemplo a ser seguido por todos aqueles decididos a perseguir a profissão de mestres de capoeira.

Distinguimos indícios de que os alunos de Mestre Bimba sempre gozaram de espaço, junto ao mestre, para a finalidade de contribuir de alguma forma na estruturação da Capoeira Regional. Decanio, um dos alunos mais influentes da Capoeira Regional, afirma claramente a efetiva participação de Cisnando na década de trinta. Outros entrevistados igualmente afirmaram terem visto ou mesmo participado de eventos com a intenção de colaborar na sistematização e para a divulgação da Capoeira Regional.

É sabido que a capoeira foi considerada, outrora, como uma atividade marginalizada, sendo reprimida e chegando mesmo a constar do Código Penal Brasileiro, mas o que tem causado espanto é como a capoeira em pouco tempo conseguiu se inserir nas instituições "nobres e conservadoras" da sociedade hegemônica.

Constatamos que, ao criar a Capoeira Regional, Mestre Bimba estabeleceu uma ruptura marcante entre a capoeira praticada na época e a sua nova proposta de capoeira, criada a partir da junção da Capoeira Angola e do Batuque. Este fato atribuiu a Bimba muitos adjetivos, a exemplo de: "o Lutero da capoeira", como disse Carybé; "o tal", como disse Fred Abreu; "um divisor de águas", como disse Muniz Sodré; "um agente de mudanças", como afirmou Luiz Renato; e "um verdadeiro mestre", com se refere Itapoan.

Este novo projeto de capoeira liderado por Mestre Bimba, e compartilhado de perto por seus alunos, extrapolou os muros do CCFR e avançou, conquistando espaços no exército, 
em escolas, universidades, clubes sociais, festas cívicas, seminários nacionais, ginásios de esportes e até apresentação para o Presidente da República, Getúlio Vargas, no Palácio do Governo em Salvador. Todo esse esforço tinha uma intenção declarada de mostrar o valor da Capoeira Regional, como luta, esporte, cultura, educação e de filosofia de vida.

Além disso, pudemos identificar vários fatos marcantes vivenciados pelos alunos de Mestre Bimba durante a sua permanência no CCFR. São fatos que, na sua maioria, revelam uma significância particular, pois entendemos que cada indivíduo tenha a sua maneira peculiar de perceber e assimilar os acontecimentos, já que tudo depende de muitos fatores, do momento psicológico, do estado emocional, da condição motivadora, da disposição, do engajamento, da capacidade de concentração, do nível de aprendizado e principalmente do amadurecimento. Por conseguinte, os olhares em direção a acontecimentos corriqueiros ou mesmo extraordinários são divergentes, têm conotações diferenciadas. Aqui, vale ressaltar, no que respeita aos alunos de Mestre Bimba, que a nossa amostra se ateve propositalmente a épocas diferentes de convivência na academia de Mestre Bimba, com a finalidade de podermos identificar melhor os fatos que marcaram essas vidas para sempre.

Uma outra investigação, cujo resultado nos chamou a atenção em especial, foi a de conhecer melhor como se dava a convivência com os diferentes na academia de Mestre Bimba e em quê este fato impactou a vida dos nossos entrevistados.

Encontramos evidências de que na academia de Mestre Bimba a convivência com os diferentes, o forte e o fraco, o hábil e o inábil, o preto, o branco e o mulato, o alto e o baixo, o escolar e o universitário, o rico e o pobre, o violento e o manso, o formado e o calouro e mais as diversidades religiosas, ideológicas e políticas, proporcionaram uma experiência sem igual à vida dos nossos informantes. Eles pontuaram alguns aspectos de real significado para eles, a exemplo da irmandade, da amizade, de "um por todos, todos por um", como se referiu Arara: "mexer com um aluno de Bimba é mexer com todo o enxame de abelhas". Para Nenel, as diferenças não se consolidavam "devido à presença equilibrada de Bimba, por esse motivo e uma atitude firme, segura do mestre as pessoas aprendiam a respeitar os limites de cada um".

Itapoan ressalta com veemência que na escola de Mestre Bimba existia uma irmandade, que ninguém queria ser melhor do que ninguém, todos tinham o foco em treinar capoeira; ficar bom era uma consequência. Na busca desse objetivo, existia, sobretudo, o respeito pela diversidade, a amizade pelo compartilhar, o zelo do aluno formado pelo aluno calouro e atitudes constantes, firmes e exemplares, de Bimba. Destacamos que a rigor esse sentimento de amizade, de reconhecimento por ter sido batizado na Capoeira Regional, perdura até os dias de hoje.

Observamos, ainda, se os alunos de Bimba têm incorporado no seu comportamento uma filosofia de vida adquirida nas rodas da Capoeira Regional, e se a colocam em prática em seu cotidiano. Dessa análise, encontramos indícios que nos levam a ter clareza de que os alunos de Mestre Bimba incorporaram de alguma maneira as lições ministradas. Eram lições bem simples e, na maioria, passadas de maneira descontraída e bem-humorada. Lições 
como: não passar em baixo de árvore polpuda; quando for dormir na casa de estranhos, fique de olho aberto contando as telhas; ao andar pela rua durante a madrugada não dobre a esquina pelo passeio, vá para o meio da rua; a fruta só dá no tempo; apenas para citar algumas lições, alguns conselhos.

Pela expressividade dos nossos entrevistados fica evidente a existência de uma filosofia de vida adquirida na Capoeira Regional, consubstanciada por uma maneira de ser diferente, observada no modo de andar, na maneira de olhar, no tom da conversa, no jeito desconfiado, na agilidade dos movimentos e na certeza de gingar sempre.

Procedendo à análise da metodologia de Mestre Bimba para o ensino da Capoeira Regional, optamos por examiná-la sob a ótica dos dois tipos de população que serviram de base ao nosso estudo empírico. Nos detemos, inicialmente, nos alunos de Mestre Bimba, cujas informações nos levam a asseverar que a grande diferença entre ele e outros mestres de capoeira de sua época está no fato de que ele pesquisou a capoeira e, de acordo com suas experiências, criou um método de ensino que desafia o tempo, e vem sendo aplicado até hoje nas aulas de capoeira.

Uma outra característica observada é a sistematização do método, que propicia um aprendizado mais rápido, eficiente, seguro, sequenciado e repleto de desafios, o que deixa os alunos ávidos por novos conhecimentos, além de ser mais participativo, praticado em duplas, e muito estimulante, pela ludicidade.

No entendimento dos mestres, contramestres e professores de capoeira da atualidade, encontramos algumas afirmações interessantes, que listamos: a) foi um artifício bastante apropriado para dar visibilidade à capoeira no seio da classe média de sua época; b) todos os movimentos das sequências estão inseridos em qualquer proposta de jogar capoeira, em qualquer estilo da atualidade; c) esta combinação de movimentos reflete o que há de mais moderno em termos de metodologia de ensino, pois proporciona o aprendizado de estruturas simples de defesa e ataque, evoluindo para estruturas mais complexas; d) acredito que este método ajuda muito no aprendizado, pois condiciona o aluno a treinar os movimentos e em consequência a aprendê-los; e) ajuda o aluno novo a ter uma melhor apresentação quando entra numa roda, pois as sequências não deixam de ser uma pequena simulação de jogo (ataque e defesa); e f) o método usado por Bimba ainda é bastante atual. "Para a nossa época é super eficiente, imagine há setenta anos atrás. O mestre 'sistematizou' o treino, importante para um melhor entendimento do aluno".

Neste resgate de algumas considerações dos nossos entrevistados percebemos o quanto suas colocações despertam neles a certeza de que Mestre Bimba usava uma metodologia eficiente para o ensino da Capoeira Regional, a qual rompe a barreira do tempo e continua sendo atual, própria para o jogo da capoeira de qualquer estilo.

Concluímos, portanto, que Mestre Bimba tinha um projeto para a sua criação, a Capoeira Regional, todavia não tinha uma instrução formal que o capacitasse a escrever suas idéias; sua vivência também era outra, seu aprendizado e conhecimento foram adquiridos através da oralidade, uma prática do seu tempo, da sua época, da sua gente. No entanto, 
Bimba, tocado pela sua genialidade e audácia, levou à frente seu projeto, compartilhando sua estruturação com seus alunos durante aproximadamente quarenta e seis anos. Essa estruturação ocorreu em épocas diferentes, o que denota a parceria constante que tinha Bimba com seus discípulos. Sabiamente, possibilitava a interferência dos alunos, experimentava, criticava: se boa, a proposta era adotada e partilhada com eles. O seu Projeto Pedagógico para a Capoeira foi se constituindo ao longo dos anos, sendo enriquecido no dia-a-dia, pois Bimba, apesar de ver além do horizonte, de enxergar à frente, balizava seu trabalho no cotidiano, vivia cada dia intensamente até finalizar sua missão em Goiânia apresentando no palco sua capoeira.

O seu Projeto Pedagógico foi composto do exame de admissão, sequência de ensino, sequência da cintura desprezada, batizado, roda de capoeira, esquenta-banho, formatura, iúna, curso de especialização, toques de berimbau, cantos, músicas, golpes e regulamento. Além de ter fundado uma escola de capoeira, o Centro de Cultura Física Regional, mais conhecida como academia de Mestre Bimba, mantinha um grupo folclórico apresentando-se regularmente em espaço próprio no Sítio Caruano, no Nordeste de Amaralina.

A ação pedagógica de Mestre Bimba era inteiramente coerente com seus propósitos e através da Capoeira Regional influenciou toda uma geração, sendo um verdadeiro construtor de homens, forjou cidadãos brasileiros e, por mérito próprio, recebeu o título de Doutor Honoris Causa da UFBA (Post-mortem), em 12 de junho de 1996. Um reconhecimento pelo seu valor como uma personalidade distinguida pelos relevantes serviços em favor da educação, da cultura e das artes, no cenário baiano, nacional e internacional.

Entendemos ser Mestre Bimba uma personalidade muito grande para caber em uma obra só, por isso recomendamos e sugerimos a ampliação deste estudo com a finalidade de produzir novas investigações na área da capoeira. Reconhecemos que urgem novas pesquisas nas mais variadas vertentes, a partir de abordagens metodológicas diferenciadas, objetivando a construção de um marco teórico sedimentado sobre estas manifestações afro-brasileiras, ricas de elementos culturais, mas carentes de pesquisas cientificas aprofundadas. 


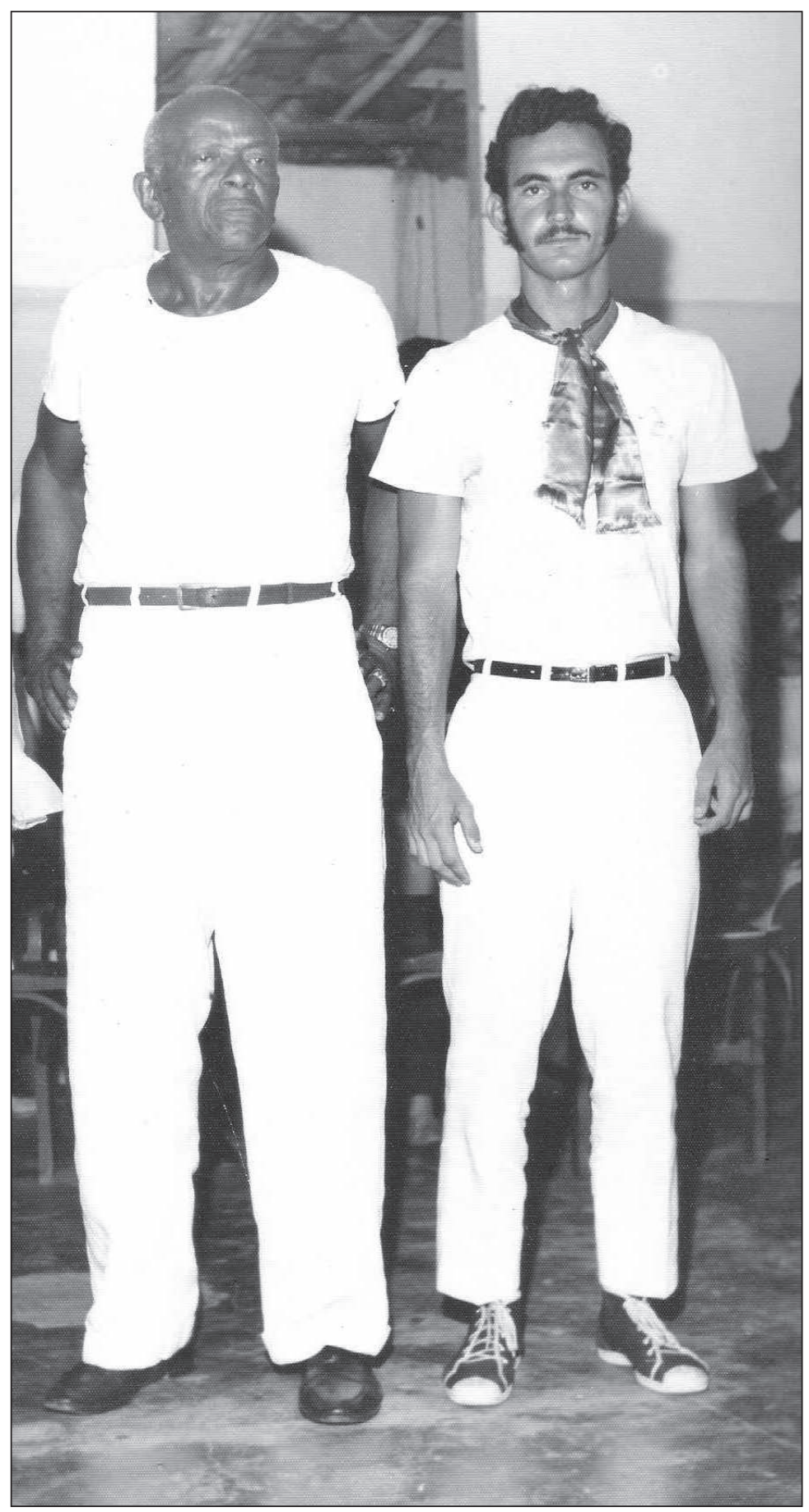

A Mestre Bimba, que um dia me pegou pelas mãos e na roda me ensinou a gingar, a ter fluidez nos movimentos do corpo e da alma; me fez olhar o mundo diferente, extrapolando o limite pobre do corpo, e a emergir no privilégio dos sonhadores de tocar as estrelas pela infinidade do espírito. 


\section{REFERÊNCIAS}

ABREU, Frederico José de. O batizado da capoeira. Negaça. Salvador, 1995. Ano III. (3): 55-58. Bimba é bamba: a capoeira no ringue. Salvador: Instituto Jair Moura, 1999.

ALENCAR, José de. Iracema: lenda do Ceará. Rio de Janeiro: B.Z.L. Carmier, 1978. ALMEIDA, Raimundo Cesar Alves. A saga do mestre Bimba. Salvador, 1994.

Bimba: perfil do mestre. Salvador: CEDUFBA, 1982.

AMADO, Jorge. Bahia de todos os santos: guias de ruas e mistérios. Rio de Janeiro: Record, 1996.

AMANDO JÚNIOR, José. O patrimônio cultural imaterial de Pelourinho. A Tarde. Salvador, 2004.

ARANTES, Antonio Augusto. O que é cultura popular. São Paulo: Brasiliense, 1981.

ARAÚJO, Paulo Coelho de. A falta de rigor científico nos estudos sobre capoeira. Comunicação apresentada ao SEMINÁRIO DE PESQUISA, SAÚDE, ALIMENTO E MEIO AMBIENTE, 9 A 11 de setembro de1992, Salvador, Bahia. digt..

ARAÚJO, Paulo Coelho de. Abordagem sócio-antropológica da luta/jogo da capoeira. Porto, Portugal: PUBLISMAI, 1997.

AREIAS, Almir das. O que é capoeira. São Paulo: Brasiliense, 1983.

ARMSTRONG, Karen. Breve história do mito. São Paulo: Companhia da Letras, 2005.

AZEVÉDO, Evilásio R. Capoeira e aptidão física. Salvador: Polícia Militar da Bahia, 1973.

BALAU, Virgínia Lopes. Texto didático: reflexões sobre análise de conteúdo e análise do discurso. 1996. 184f. Dissertação (Mestrado em Psicologia da Educação). Pontifícia Universidade Católica de São Paulo. São Paulo.

BARDIN, Laurence. Análise de conteúdo. Lisboa: Edições 70, 1977.

BARBIERI, Cesar Augustus S. Um jeito brasileiro de aprender a ser. Brasília: CIDOCA/ DF, 1993.

O que a escola faz com que o povo cria: até a capoeira entrou na dança. 2003. 391f. Tese (Doutorado em Educação). Universidade Federal de São Carlos. São Paulo.

BARRETO, Margarita. Turismo e legado cultural. Campinas: Papirus, 2002.

. Manual de iniciação ao estudo do turismo. Campinas: Papirus, 1995.

BASTOS, Maria Helena Câmara. Pro pátria laboremos: Joaquim José de Menezes Vieira (1848-1897). Bragança Paulista: EDUSF, 2002.

BIMBA desafia os capoeiristas bahianos. Diário da Bahia, Salvador: 28 jan. 1936.

BOAVENTURA, Edivaldo. Baianização do currículo. A Tarde, Salvador: 8 jan.1988. Educação, p.5.

A capoeira de beca. A Tarde, Salvador: 16 set.1999. Opinião, p.5. 
. Como ordenar as idéias. São Paulo: Ática, 1888.

. Educação, cultura e direito: coletânea em homenagem a Edivaldo M. Boaventura.

(Org.) Alfredo Eurico Rodrigues Matta [et al]. Salvador: Edufba, 2004.

. Gente da Bahia. Rio de Janeiro: Tempo Brasileiro, 1990.

. Metodologia da pesquisa. São Paulo: Atlas, 2004.

. O território da palavra. Salvador: Ianamá, 2001.

. Educação aberta e qualidade do relacionamento professor-aluno. In: Algumas reflexões sobre educação, Salvador; FACED/UFBA, 1992. p.71-86.

. Proposta de pesquisa para o doutorado. In: SILVA, Ana Célia da; BOAVENTURA, Edivaldo, M.(Org.), Salvador: Programa de Pós-Graduação em Educação da; FACED/-UFBA, 2005. p.21-56.

BOAVENTURA, Edivaldo M.; SILVA, Ana Célia da;(Org.) O terreiro, a quadra e a roda: formas de alternativa de educação da criança negra em Salvador. Salvador: Programa de Pós-Graduação em Educação da FACED/UFBA, 2005.

BOBIO, Norberto; MATTEUCCI, Nicola; PASQUINO, Giafranco. Dicionário de política. Brasília: Edunb,1992.

BOLA SETE, Mestre. A capoeira angola na Bahia. Salvador: Fundação das Artes,1989.

BONATES, KK. Iúna mandigueira: a ave símbolo da capoeira. Manaus: Fênix, 1999.

BORDENAVE, Juan E. Díaz. O que é comunicação. São Paulo: Brasiliense, 2005.

BLUTEAU, Rafhael. Vocabulário português e latino. Coimbra: Editora Colégios das Artes da Companhia de Jesus, 1712.

BRASIL. Conselho Federal de Educação. Resolução n. ${ }^{\circ} 03$ de 16 de junho de 1987. Diário Oficial da União, 10 de setembro de 1987. p. 14682

BRASIL. Constituição (1988). Constituição da República Federativa do Brasil. Brasília, DF: Senado, 1988.

BRASIL. Ministério da Cultura. Disponível em: http://www.cultura.gov.br/noticias/noticias_do_ minc/index.php? $\mathrm{p}=12383 \&$ more $=1 \& \mathrm{c}=1 \& \mathrm{pb}=1>$. Acesso em: 15 nov.2005.

BRASIL. Universidade Federal de Uberlândia. Resolução nº 03 de 27 de junho de 2003, Uberlândia, M. G.

BULE-BULE. Bimba espalhou capoeira nas praças do mundo inteiro. Salvador: Liceu de Artes e Ofícios da Bahia, 1992.

BURLAMAQUI, Anibal. Gymnastica Nacional (capoeiragem) methodisada e regrada. Rio de Janeiro, 1928.

CAILLOIS, Roger. Os jogos e os homens. Lisboa: Gallimard, 1990.

CALASANS, José et al. Cadernos Antonio Vianna. Salvador: IHGB, 1976.

CAMPBELL, Joseph. O poder do mito. São Paulo: Palas Athenas, 1998. 
CAPOEIRA, Nestor. Capoeira: os fundamentos da malícia. São Paulo: Record, 1998.

Capoeira: o pequeno manual do jogador. São Paulo: Ground, 1981.

CAMARÁ CAPOEIRA. São Paulo: A CAPA. 1999. Mensal.

CAMPOS, Helio. Capoeira, do popular para a universidade; uma trajetória de resistência. 1999. 149 f. Tese (Livre Docência em Educação Física). American World University. Iowa, USA.

CAMPOS, Helio. Capoeira na escola. Salvador: Presscolor, 1990.

CAMPOS, Helio. Capoeira na escola. Salvador: Edufba, 2001.

CAMPOS, Helio. Capoeira na universidade: uma trajetória de resistência. Salvador: Edufba, 2001.

CAMPOS, Helio. A Política de expansão da Capoeira Regional. In: MATTA, Alfredo Eurico Rodrigues (Org. [et al). Educação, cultura e direito: coletânea em homenagem a Edivaldo M. Boaventura. Salvador: Edufba, 2004.

CAMPOS, Helio. Capoeira, o método de ginástica brasileiro. Negaça. Salvador, 1992. Ano I. (1): 46-49.

CARYBÉ. Disponível em http://www.facom.ufba.br/com024/carybe/principa.htm > . Acesso em: 10 ago. 2005.

CARMO-NETO, Dionísio Gomes do. Metodologia científica para principiantes, Salvador: Editora Universitária Americana, 1993.

CERVO, A L. \& BERVIAN, P. A. Metodologia Científica. São Paulo: McGraw-Hill, 1983.

CHEDIAK, Adriano. Da senzala para o campus, Revista Capoeira: Arte e Luta Brasileira, São Paulo: 1998. Ano I (1): 03 -12.

. Da senzala para o campus, Revista Capoeira: Arte e Luta Brasileira, São Paulo: 1998. Ano I (2): 07-12.

. I Festival Ford Universitário de Capoeira, Revista Capoeira: Arte e Luta Brasileira, São Paulo: Ano II (10).

CHIZZOTTI, Antonio. Pesquisa em ciências humanas e sociais. São Paulo: Cortez, 2001.

COSTA, Reginaldo da Silveira. Capoeira: o caminho do berimbau. Brasília: Thesaurus. 1993.

COUTINHO, Daniel. ABC da Capoeira Angola: manuscrito de mestre Noronha. Brasília: DEFER (CIDOCA/DF), 1993.

DECANIO FILHO, Angelo A. A herança de mestre Bimba. Salvador, 1996.

DECANIO FILHO, Angelo A. A herança de Pastinha. Salvador, 1996.

DECANIO FILHO, Angelo A. Revista da Bahia: Transe capoeirano: estado de consciência modificado na capoeira, Salvador: Egba, 2001. No. 33. Jul. p.43-65.

FALCÃO, José Luiz Cirqueira. A escolarização da capoeira. Brasília: Royal Court, 1996. -14 . . Capoeira e/na educação física, Sprint magazine, Rio de Janeiro: 1995. Ano XIV (79):10 
FERRARO, Alcyr Naidiro Fraga. A educação física na Bahia: memórias de um professor. Salvador: Edufba, 1991.

FERREIRA, Emilia Biancardi. Ôlelê maculelê. Brasília: Edição Especial, 1989.

FREIRE, Paulo. Pedagogia da autonomia: saberes necessários à prática educativa. São Paulo: Paz e Terra, 1996.

GASPARIN, João Luiz. Uma didática para a pedagogia histórico-crítica. São Paulo: Autores Associados, 2003.

GIL, Antonio Carlos. Como elaborar projetos de pesquisa. São Paulo: Atlas, 1996.

GINGA NA CASA BRANCA. Aqui Salvador. Salvador: Correio da Bahia, jul, 2001.

GÓES, Odilon Jorge Daltro. Os efeitos do treinamento de musculação na resistência muscular localizada, para os estudantes de $1^{\circ}$ e $2^{\circ}$ graus, na faixa etária de 16 a 18 anos no Colégio Carneiro Ribeiro Filho. 1985. 75f. Monografia (Curso de Especialização em Treinamento Desportivo). Universidade Gama Filho, Rio de Janeiro.

GOLDENBERG, Mirian. A arte de pesquisar. Rio de Janeiro: Record, 2003.

GONÇALVES, Raquel. O selo de Salomão. Disponível em <http://www.triplov.com/alquimias/ rgoncalves1.htm > . Acesso em: 25 jan. 2006.

GUERRA, Martha de Oliveira; CASTRO Nancy Campi de. Como fazer um projeto de pesquisa. Juiz de Fora: Editora UFJF, 1997.

HOFMANN, Helmut. Como trabalhar intuitivamente com os símbolos: inspiração, meditação, proteção e cura. São Paulo: Pensamento, 1999.

HUIZINGA, Johan. Homo ludens: o jogo como elemento da cultura. São Paulo: Perspectiva, 1990 .

JACOB, Adriana. Bimba: Rei negro. Correio da Bahia, Salvador, Caderno Domingo Repórter, p.1-7, 14 set. 2003.

JAFFÉ, Aniela. O simbolismo nas artes plásticas. In. __. O homem e seus símbolos: Tradução de Maria Lucia Pinho. Rio de Janeiro: Nova Fronteira, 1977.

JUNG, Carl Gustav. Os arquétipos e o inconsciente coletivo. Petrópolis: Vozes, 2000.

JUNG, Carl Gustav et al. O homem e seus símbolos. Rio de Janeiro: Nova Fronteira, 1977.

KOTLER, Philip. Administração de marketing: análise, planejamento, implementação e controle. São Paulo: Atlas, 1998.

LAKARTOS, Eva Maria; MARCONI, Marina de Andrade. Metodologia do trabalho científico. São Paulo: Atlas, 1992.

LARAIA, Roque de Barros. Cultura: um conceito antropológico. Rio de Janeiro: Jorge Zahar, 2002.

LE GOFF, J. História e memória. Campinas: Editora da Unicamp, 1990.

LELOUP, Jean-Yves. O corpo e seus símbolos: uma antropologia essencial. In: LIMA, Lise Mary Alves de. Petrópolis, RJ: Vozes, 1998. 
LIBÂNIO, José Carlos. Democratização da escola pública: pedagogia crítico-social dos conteúdos. São Paulo: Loyola, 2002.

LIMA, Mano. Dicionário de Capoeira. Brasília, 2005.

LIMA, Paulo Costa. Ernest Widmer e o ensino de composição musical na Bahia. Salvador: FAZCULTURA/COPENE, 1999.

LOPES, André Luiz Lacé. Administração esportiva: administração pública e outras administrações. Brasília: DEFER/CIDOCA, 1995.

LOPES, Augusto José Fascio. O maculelê. Revista Capoeira. São Paulo: 1998. Ano 1 (03): 40-41.

LUBISCO, Nídia M. L.; VIEIRA, Sônia Chagas. Manual de estilo acadêmico: monografias, dissertações e teses. Salvador: EDUFBA, 2002.

LUCKESI, Cipriano Carlos. Filosofia da educação. São Paulo: Cortez, 1994.

LUCKESI, Cipriano Carlos. Desenvolvimento dos estados de consciência e ludicidade. Disponível em http:/biossintese.psc.Br/Dccongress2000. Acesso em: 20 nov. 2004.

LUDKE, Menga; ANDRÉ, Marli E. D. A. Pesquisa em educação: abordagens qualitativas. São Paulo: EPU, 2003.

LUSSAC, Ricardo Martins Porto. Estudo da metodologia do ensino da capoeira. Sprint magazine, Rio de Janeiro: 1996. Ano XV. (84):36-38.

LUZ, Marco Aurélio. Do tronco ao opa exin: memória e dinâmica da tradição africana-brasileira. Salvador: Secneb, 1993.

MACHADO, Vanda. O negro constituinte da sua liberdade. In: LUZ Marco Aurélio (Org) Identidade negra e educação. Salvador: Edições Ianamá, 1989.

MAHAPESQUISA Simbologia: Selo de Salomão. Disponível em: < http://mahabaratha.vilabol. uol.com.br/ensaios/simbologia00estrela.htm. Acesso em: 25 jan. 2006.

MARCELINO, Nelson Carvalho. Estudos do lazer: uma introdução. São Paulo: Autores Associados, 1996.

MARIA, Joaquim Parron. Novos paradigmas pedagógicos: para uma filosofia da educação. São Paulo: Paulus, 1996.

MARINHO, Inezil Penna \& ACCIOLY, Aluizio Ramos. História e organização da educação física e dos desportos. Rio de Janeiro, 1956.

MARINHO, Inezil Penna. A ginástica brasileira. Brasília, 1982.

. Introdução ao estudo da filosofia da educação física e dos desportos. Brasília: Horizonte, 1984.

. Sistemas e métodos de educação física. São Paulo: sd.

. Rui Barbosa paladino da educação física no Brasil. Brasília: Horizonte, 1980.

. História da educação física no Brasil. São Paulo: CIA Brasil, sd.

. Introdução ao estudo do folclore brasileiro. Brasília: Horizonte, 1980. 
MATTEDI, Claudia. Senna: um novo Mito Nacional e o modo de ser brasileiro. 1997. 67f. Monografia (Trabalho de Conclusão do Curso de Ciências Sociais). Faculdade de Filosofia e Ciências Humanas da Universidade Federal da Bahia, Salvador.

MATTOS, Haron Crisóstomo Castñon. Os efeitos da prática da capoeira sobre força, flexibilidade, resistência, habilidade específica e composição corporal. 1994. 57f. Monografia (Programa de Iniciação Científica). Faculdade de Educação Física e Desportos da Universidade Federal de Juiz de Fora, Juiz de Fora.

MAY, Rollo. A procura do mito. São Paulo: Manole, 1993.

MEGALI, Nilza B. Folclore brasileiro. Petrópolis: Vozes, 2001.

MENEZES, Antonio Carlos de. A preparação física do atleta de capoeira. Jornal Muzenza. Curitiba, 1995. (7): 6-7.

MERCÉS, Aristides Pupo. Manual de ensino da capoeira. Salvador: ACAL, 1981.

Cartilha de capoeira. Salvador: ACAL, 1996.

MESTRE Bimba. campeão na capoeira, desafia todos os luctadores bahianos. A Tarde, Salvador, 16 de Março. 1936.

PASTINHA, Mestre. Capoeira Angola. Salvador: Fundação Cultural do Estado da Bahia, 1988.

MINAYO, Cecília Souza (Org.). Pesquisa social. Petrópolis: Vozes, 2002.

MOREIRA, Sérgio. Cara brasileira. Brasília: Sebrae, 2002. ISBN: 85-7333-329-4.

MOURA, Jair. Capoeira Regional baiana. O Município, Salvador, 1968. Ano II, (1): 4-5,

- Capoeira, a luta regional baiana. Cadernos de cultura, N. ${ }^{\circ} 01$, Salvador: Secretaria

Municipal de Educação e Cultura, 1979, p. 39.

MOURA, Jair. Mestre Bimba: a crônica da capoeiragem. Salvador, 1993.

NASSER, Maria Celina de Q. Carrera. O que dizem os símbolos. São Paulo: Paulus, 2003.

NOTÍCIAS ESPORTIVAS. Salvador: Ano I, nº 21, mar. 1969.

ORTIZ, Renato. Cultura brasileira \& identidade nacional. São Paulo: Brasiliense, 1998.

PAIVA, Pedro Alvares. Educação física: principais sistemas e métodos. Minas Gerais: U. F. de Viçosa, 1980.

PATROCÍNIO, Nacimária Correia do. Por uma educação pluricultural. In: LUZ Marco Aurélio (Org), Identidade negra e educação. Salvador: Ianamá, 1989.

PEIRCE, Charles S. Semiótica. São Paulo: Perspectiva, 1999.

PIRES, Antônio Liberac Cardoso Simões. Bimba, Pastinha e Besouro Mangangá: três personagens da capoeira baiana. Tocantins, Goiânia: NEAB/Grafset, 2002.

PIRES, Wilson. Memórias do capoeirista Maxixi. [no prelo], 2005.

PORTO FILHO, Ubaldo. Rio Vermelho. Salvador: AMARV, 1991.

PRATICANDO CAPOEIRA. São Paulo. Editora D+T, ANO I, n. 2. 
PRATICANDO CAPOEIRA. São Paulo. Editora D+T, ANO I, n. 4.

PRATICANDO CAPOEIRA. São Paulo. Editora D+T, ANO I, n. 10.

PRATICANDO CAPOEIRA. São Paulo. Editora D+T, ANO II, n. 17.

PRATICANDO CAPOEIRA. São Paulo. Editora D+T, ANO II, n. 18.

PRATICANDO CAPOEIRA. São Paulo. Editora D+T, ANO II, n. 26.

PRATICANDO CAPOEIRA. São Paulo. Editora D+T, ANO II, n. 27.

PRATICANDO CAPOEIRA. São Paulo. Editora D+T, ANO II, n. 30.

REIS, Letícia Vidor de Souza. O mundo de pernas para o ar: a capoeira no Brasil. São Paulo: Publisher Brasil, 1997.

REIS, André Luiz Teixeira, Brincando de capoeira: recreação e lazer na escola. Brasília: Valcy, 1997.

REIS, André Luiz Teixeira. Educação física \& capoeira: saúde e qualidade de vida. Thesaurus, 2001.

REGO, Waldeloir. Capoeira Angola: ensaio sócio-etnográfico. Salvador: Itapuã,1968.

REVISTA DA BAHIA, Salvador: egba, 2001.

REVISTA DO PATRIMÔNIO HISTÓRICO E ARTÍSTICO NACIONAL, Rio de Janeiro: Negro Brasileiro Negro, No 25, 1997.

RODRIGUES, J. Barbosa. Paranduba Amazonense ou Kochima-Uara Poranduba. Rio de Janeiro: Tipografia de Leuzinger e Filhos, 1872/1887.

RODRIQUES, Marly; FUNAY, Pedro Paulo; PINSKY, Jaime (Org.). Tưrismo e patrimônio cultural. São Paulo: Contexto, 2002.

RODRIGUES, Silvio Claudio Pereira. Análise bidimensional da ginga na capoeira. Kinesis, Santa Maria: 1991 (8): 91-107.

RUDIO, Frans Victor. Introdução ao projeto de pesquisa científica. Petrópolis: Vozes, 1999.

SALVADOR. Decreto $n^{\circ} 5.009$, de 24 de fevereiro de 1977. Dispõe sobre a rua do Nordeste, citada no artigo anterior, passa a ser denominada RUA MESTRE BIMBA.

SANTANA, Mestre. Iniciação à capoeira. São Paulo: Ground, 1989.

SANTOS, Esdras M. Conversando sobre capoeira. São José dos Campos: JAC, 1996.

SANTOS, Luis Silva. Educação - educação física - capoeira. Maringá: Fundação Universidade Estadual de Maringá, 1990.

. Capoeira: uma expressão antropológica da cultura brasileira. Maringá: Programa de Pós-Graduação em Geografia da Universidade Estadual de Maringá, 2002.

La Capoeira como expresión antropológica de la cultura brasileña. 1997. $458 \mathrm{f}$. Tese (Doutorado em Antropologia Social). Facultad de Geografia e Historia, Universidad de Barcelona. Barcelona.

SANTOS, Marco Antonio Bechara. Capoeira: um esporte que educa. Jornal Muzenza, Curitiba: 
1995. Ano 1 (07): 4-5.

SAVIANI, Demerval. Escola e democracia. Campinas: Autores Associados, 2001.

SENNA, Carlos. Capoeira: percurso. Salvador, 1990.

- Capoeira: arte marcial brasileira, Cadernos de cultura, n. 03, Salvador: Secretaria

Municipal de Educação e Cultura. Salvador, 1980.p.96

SÉRGIO, Manuel. Para uma nova dimensão do desporto. Lisboa, Portugal: Edição da Direção Geral de Educação Física e Desportos, 1974.

SEVERINO, Antônio Joaquim. Metodologia do trabalho científico. São Paulo: Cortez, 2000.

SHARP, Daryl. Léxico junguiano. São Paulo: Cultrix, 1991.

SIEGA, Carson. Cuidados e contra-indicações. Jornal Muzenza. Curitiba: 1998. Ano 4 (33):911.

SILVA, Gladson de Oliveira. Capoeira do engenho à universidade. São Paulo: CEPEUSP, 1995. . Capoeira. São Paulo: CEPEUSP,1989.

SILVA, Gladson de Oliveira. Novos status mas com tradição. Revista Capoeira. São Paulo: 1999. Ano II (04): 26-27.

SILVEIRA, Nise da. O mundo das imagens. São Paulo: Ática, 2000.

SOARES, Carlos Eugênio Líbano. A negregada instituição. Rio de Janeiro: Secretaria Municipal de Cultura, 1994.

SOBRAL, Francisco. Introdução à educação física. Lisboa, Portugal: Livros Horizonte, 1980.

SODRÉ, Muniz. O Brasil simulado e o real. Rio de Janeiro: Rio Fundo, 1991.

SODRÉ, Muniz. Mestre Bimba: corpo de mandinga. Rio de Janeiro: Manati, 2002.

SODRÉ, Nelson Werneck. Síntese de história da cultura brasileira. Rio de janeiro: Civilização Brasileira, 1972.

SOUZA, Osvaldo de. Capoeira Regional. Goiânia: Kelps, 2000.

STEIN, Murray. Jung: o mapa da alma. São Paulo: Cultrix, 1998.

TAVARES, Luis Carlos (Org.). Cadernos de capoeira. Aracaju: Universidade Federal de Sergipe, 1994.

SZYMANSKI, Heloisa (Org.). A entrevista na pesquisa em educação: a prática reflexiva. Brasília: Líber Livro, 2004.

TOLEDO, M. A. P. Legislação da educação física/desportos, 1983

TRIVIÑOS, Augusto. N. S. Introdução à pesquisa em ciências sociais. São Paulo: Atlas, 1995 TUBINO, Manoel José Gomes. Dimensões sociais do esporte. São Paulo: Cortez, 1992.

Esporte e cultura física. São Paulo: IBRASA, 1992.

UMA FESTA esportiva original. A Tarde., Salvador: 3 de dez. 1934. 
UFBA CONCEDE TÍTULO AO CAPOEIRISTA MESTRE BIMBA. Tribuna da Bahia. Salvador, 27 de abr. 1996.

VIANNA, Heraldo Marelim. Pesquisa em educação: a observação. Brasília: Plano, 2003.

VIEIRA, Luís Renato. O jogo de capoeira. Rio de Janeiro: Sprint, 1995.

VIEIRA, Luís Renato. Capoeira: os primeiros momentos de sua história. Revista Capoeira, São Paulo: 1998. Ano 1 (01): 42-44.

VIEIRA, Luís Renato. A capoeira angola. Revista Capoeira, São Paulo:1998. Ano 1 (02): 44-45

VIEIRA, Luís Renato. De prática marginal à arte marcial brasileira. Revista Capoeira, São Paulo: 1998. Ano 1 (03): 42-43.

VIEIRA, Luís Renato. A capoeira e a cultura internacional-popular. Revista Praticando Capoeira, São Paulo: 2002. Ano II (18): 10-11.

ZULU, Mestre. Idiopráxis da capoeira. Brasília: Fundação Educacional do Distrito Federal FEDF, 1995.

ZIGGIATTI, Manoela. João Grande foi à América mostrar a capoeira do Brasil. Universo Capoeira. São Paulo, Ano.1, n. 4, 1999.

\section{REFERÊNCIAS ICONOGRÁFICAS}

Acervo do Autor

Acervo do Instituto Jair Moura

Acervo do Mestre Itapoan

$4^{a}$ Divisão. Prancha 18. Apresentação e texto de Herculano Gomes Mathias. Rio de Janeiro, Tecnoprint. 1980. p.77 (Edições de Ouro).

PRANCHAS da Viagem Pitoresca e Histórica através do Brasil. DEBRET. Vol. 2. Prancha 14. Apresentação e texto de Herculano Gomes Mathias. Rio de Janeiro, Tecnoprint. 1980. p.43 (Edições de Ouro).

PRANCHAS da Viagem Pitoresca e Histórica através do Brasil. RUGENDAS.

\section{REFERÊNCIAS DE IMAGENS EM MOVIMENTO}

DANÇA DE GUERRA. Produção e Direção: Jair Moura. Texto Sampaio Gerbase. Produtor Associado: Agnaldo Azevedo,1 filme (17,32 min.). Salvador: 1969.

LA “CAPOEIRAGEM” em Bahia. Realización: TV BAHIA. Dirección: Libretos y Edicíón: José Humberto. Producción: Uirá Iracema. Narración; Geraldo Cohen, Johny Santos. Filme, (57 min.), 2000.

MANDINGA EM MANHATTAN. Direção: Lázaro Farias. Vídeo documentário. Roteiro: Isabella Lago. Produção Executiva: Gorette Randan. 1.DVD. Casa de Cinema da Bahia. Salvador, 2005.

MESTRE BIMBA DOUTOR HONORIS CAUSA DA UFBA. Organizador: Raimundo César 
Alves de Almeida [Mestre Itapoan]. 1 fita de vídeo (60 min.) VHS, son., color. Salvador, 1996. MESTRE BIMBA, a Capoeira Iluminada. Direção: Luiz Fernando Goulart. Produção: Lúmen Produções. Roteiro: Luiz Carlos Marciel. Baseado no livro "Mestre Bimba" Corpo de mandinga, de Muniz Sodré. Brasil. Filme documentário (79 min.). 2005.

PARANAÉ CAPOEIRA: a expansão da Capoeira Regional. Organizador: Contramestre Minhoca. Produção: Maxhouse. 1 DVD. Salvador, 2005.

PASTINHA: uma vida pela capoeira. Direção: Antonio Carlos Muricy. Brian Swell Produções Cinematográficas. Editora Praticando Capoeira, 1999.

VADIAÇÃO. Direção: Alexandre Robato Filho. Salvador, 1954.

\section{DOCUMENTO SONORO E MUSICAL}

ASSOCIAÇÃO BRASILEIRA DOS PROFESSORES DE CAPOEIRA. Produção: ABPC. Projeto Gráfico e Fotilito: MCK multimídia. 1 CD, Goiânia, 1995.

BAHIA ARTE MESTRE PIAUÍ. Direção: Mestre Piauí. 1 CD

CAMUJERÉ CAPOEIRA: Cheguei para ficar. Contramestre Tosta. Direção: Tosta, Coringa e Bal. Coordenação; Aruanda. Produção: Alvinho. 1 CD. V. 1.

CAPOEIRA ANGOLA. Mestre João Grande. New York, USA. 1 CD.

CAPOEIRA FABINHO: Grupo ULBRA. Direção: Fábio Camargo. Engenheiro de Gravação. Diego K. Sgrillo. 1 CD. Porto Alegre, 1999.

CAPOEIRA NOS JEBS. Cantigas Programa Nacional de Capoeira. Gravação: Conservatório de Música de Pernambuco. 1 disco sonoro. Long Play.

CAPOEIRA PARA CRIANÇAS. Produção: Paranaê Capoeira. Direção: Minhoca. Studio HS. 1 CD, Salvador, 2005.

CAPOEIRA: Mestre Canjiquinha \& Mestre Waldemar. Cordões de Ouro Promoções Artísticas. CURSO DE CAPOEIRA REGIONAL, MESTRE BIMBA. RC-Disco. 1 disco sonoro. Long Play. Salvador.

GRUPO MOLAS: Mestre Lucas. Direção: Mestre Lucas. Editoração: ARAGRAF. 1 CD. Aracajú, 1998.

GRUPO MUZENZA. Direção: Mestre Burguês. 1 CD. São Paulo.

GRUPO MUZENZA: Mestre Burguês. Direção: Mestre Burguês. 1 disco sonoro. Long Play. V2. Curitiba.

MESTRE BIMBA: Curso de Capoeira Regional. 1.CD.

MESTRE EZIQUIEL. Projeto: Sérgio Graça e Queijadinha d'Angola. Produção: Liceu Artes e Ofícios da Bahia, Oficina do Movimento. Gravação: Felipe Cavallere. 1 disco sonoro. Long Play, Salvador.

MESTRE ITAPOAN \& GRUPO GINGA: Capoeira 100\% Regional. Direção Artística: George 
Câmara. Produção: George Câmara e Mestre Itapoan. 1 CD, Salvador, 1999.

MESTRE ITAPOAN \& GRUPO GINGA: Vem Camará. Direção Artística: Mestre Itapoan, Mestre Xaréu e Mestre Careca. Produzido: Praticando Capoeira. 1 CD, Salvador, 2002.

MESTRES JOÃO GRANDE \& JOÃO PEQUENO. Projeto: Sérgio Graça e Queijadinha d'Angola. Produção: Liceu Artes e Ofícios da Bahia, Oficina do Movimento. Gravação: Felipe Cavallere. 1 disco sonoro. Long Play, Salvador.

MÚSICA DE CAPOEIRA. Mestre Luiz Renato. Direção: Fernando C. de Araújo. 1 CD.

SOU FELIZ!!! SOU CAPOEIRA REGIONAL. Produção: Grupo Porto da Barra Montreal/Canadá. Direção Artística: Careca. 1 CD

UM ENCONTRO DE AMIGOS: Coletânea Inédita. Produção: Praticando Capoeira. 1 CD. 


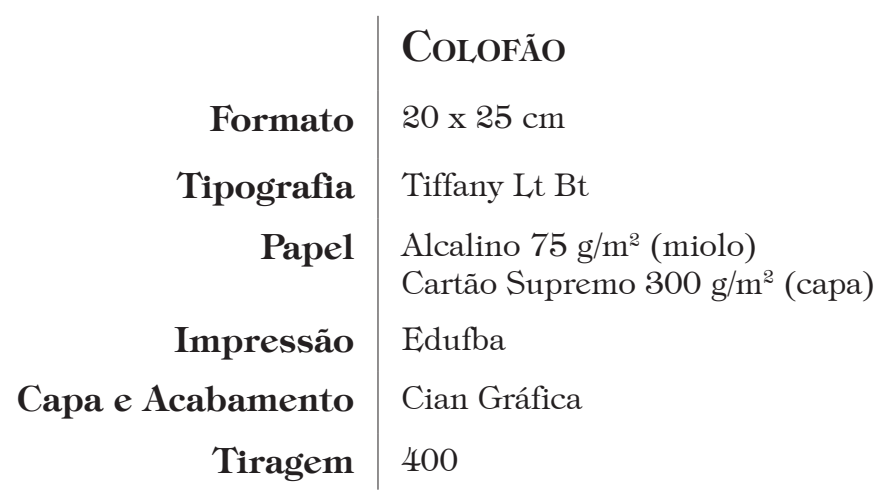

